\title{
Challenges to Advanced Nursing Practice in Nigeria, Possible Ways Forward
}

\author{
Chukwu Stella Nchekwubedi* \\ Department of Nursing Science, Ebonyi State University, Abakaliki, Ebonyi State, Nigeria

\section{*Corresponding Author} \\ Chukwu Stella Nchekwubedi
}

\section{Article History}

Received: 27.07.2020

Accepted: 05.08.2020

Published: 13.08.2020

\begin{abstract}
In line with the fundamental responsibilities of a nurse to promote health, prevent illness, restore health and to alleviate suffering, advanced practice nursing roles are developing globally to provide expert nursing care at an advanced level of practice though these are not without challenges to the practice. In Nigeria, advanced practice nursing is still evolving and for the practice to be effectively and successfully adopted, the many challenges and limitations to nursing practice in the country need to be identified and solutions proffered. This paper seeks to explain the concept of Advanced Nursing practice, the global practice taking into cognizance the challenges/barriers to the practice and the strategies adopted to overcome these barriers. Also the challenges to the practice in Nigeria will also be discussed and possible ways forward recommended.
\end{abstract}

Keywords: advanced practice nursing, nursing practice, nursing education, challenges, Nigeria.

\section{INTRODUCTION}

In line with the fundamental responsibilities of a nurse to promote health, prevent illness, and restore health and to alleviate suffering, advanced practice nursing roles are developing though these are not without challenges to the practice.

Advanced practice nursing roles are developing globally and opportunities for advanced practice nursing (APN) are expanding worldwide due to the need for expert nursing care at an advanced level of practice [1].

In Nigeria, due to the evolving changes in healthcare delivery there is need to provide expert nursing care at an advanced level especially at the community levels.

Advanced practice Nursing is the term used to define a level of Nursing Practice that uses comprehensive skills, experience and knowledge in nursing care. Nurse practitioners are clinicians that blend clinical expertise in diagnosing and treating health conditions with an added emphasis on disease prevention and health management.

According to the International Council of Nursing [2], an Advanced Practice Nurse is defined as: "A registered nurse who has acquired the expert knowledge base, complex decision-making and clinical competency skills for expanded practice, and is granted the credentialing of the country he /she is recognized to practice."

The basis of advanced practice is the high degree of knowledge, skill and experience applied in the nursepatient/client relationship in order to achieve optimal outcomes through critical analysis, problem solving and accurate decision making [3]. The addition of nurses in advanced practice in the emergency settings enabled physicians to pay greater attention to patients of higher complexity and acuity, thereby improving access to prompt emergency care [4].

Advanced practice Nursing (APN) came into existence globally since the 1960's when healthcare systems and governments around the world began to recognize it "as an essential vehicle for innovation and healthcare reform to

Copyright @ 2020: This is an open-access article distributed under the terms of the Creative Commons Attribution license which permits unrestricted use, distribution, and reproduction in any medium for non commercial use (NonCommercial, or CC-BY-NC) provided the original author and source are credited. 
provide more effective and sustainable models of healthcare" [5]. APNs have become a well established professional group in the USA, Australia, Canada, New Zealand, Great Britain and Holland.

An advanced practice Registered nurse (APRN) is a nurse with post graduate education (at least a Master's degree) in Nursing and APRN is a term used to encompass certified nurse midwife, certified registered nurse anesthetist, clinical nurse specialist and nurse practitioner [1]. Advanced practice nurses build on their clinical expertise in a specialty area by integrating research, education, leadership, consultation and collaboration and a health systems approach.

Global characteristics of the APRN role according to the International council of Nursing [6] include right to diagnose, authority to prescribe medication, authority to prescribe treatment, authority to refer clients to other professionals, authority to admit patients to hospital, legislation to confer and protect the title "Nurse practitioner/advanced practice Nurse", legislation or some other form of regulatory mechanism specific to advanced practice nurses and officially recognized titles for nurses working in advanced practice roles.

The general functions of an Advanced Nurse Practitioner include

- Diagnosing patients

- Performing physical examinations and other examinations including psychological, psychosocial, functional and developmental tests and diagnostic

- Ordering laboratory tests and interpreting results,

- Developing differential diagnoses,

- Maintaining patient records and ensuring patient privacy and clinic or hospital compliance

- Evaluating patient's progress and responses to various treatments to modify treatment and care plans as necessary,

- $\quad$ Providing counseling to patients and families

- Referring patients to other treatment facilities

- Providing consultations to patients who have yet to choose a course of action

- Dispensing medications to patients

- $\quad$ Participating in research studies [7].

In Nigeria, the advanced practice role is still in slow evolution. The two advanced practice roles recognized at this time are the Nurse Anaesthetist and the Nurse Midwife [8] but then both of these roles are post nursing training certificates under the jurisdiction of the Nursing and Midwifery Council of Nigeria (NMC) and are obtained as diplomas after basic Nursing training is completed [9]. This does not flow with the backdrop that APRNs are prepared with advanced didactic and clinical education, knowledge, skills and scope of practice in Nursing through post graduate education. Though there are Nurse Educators, researchers and administrators with post graduate education who may demonstrate advanced nursing practice in their positions, they cannot be considered as advance practice Nurses because they do not engage in clinical care.

Advanced nursing practice is important in Nigeria as it will help in solving people's health problem. It will enable Nurses to be available to help in the health system where doctors are not enough especially in the rural areas and communities where there are no doctors and the people patronize quacks bearing the name "Doctor". It will equally help to save time and cost for patients and also reduce stress on the patients especially in the hospitals.

Nursing practice in Nigeria needs to come up to standards obtainable in the developed countries and for these to be achieved, challenges facing nursing practice in Nigeria needs to be identified and eliminated to promote the advancement of the nursing profession.

\section{Global challenges to the advanced practice nursing role}

Many challenges/barriers have been identified in relation to NP-APN practice. These include access to educational programs globally, lack of understanding of the NP-ANP role, lack of respect of the nursing profession, variation in scope of practice, prescriptive authority, licensure requirement.

Also specific country regulations were identified to impose restrictions on various aspects of APRN care including legal/regulatory barriers, institutional barriers and cultural barriers. Specific examples include whether APRNs can admit patients, serve as primary care providers, sign orders for long term care services or be recognized by insurance companies as providers [10].

Equally some healthcare institutions medical staff by-laws restrict who can admit patients or perform specific procedures even if a qualified APRN is available. 
Other identified challenges include

- Insufficient nursing education

- Focus on the medical mode

- Dominance of the medical profession

- Issues related to credentialing

- Standardized educational requirements

- Supervision requirements

- Role recognition

- Independent practice authority

- Certification requirements $[10,11]$

\section{Challenges to advanced nursing practice in Nigeria}

Nursing profession in Nigeria is still facing a lot of challenges both in education and practice and before advanced Nursing practice could be fully adopted in Nigeria at all levels of health care not just the primary levels, those challenges should be met if not totally solved. The challenges include

\section{Standard of Nursing Education in Nigeria}

It is not an uncommon knowledge that the quality of education has deteriorated in the country, and nursing education is not an exception. Despite the various schools of nursing, schools of midwifery and universities in the country, the quality of nursing education is low and is not at par with what is obtainable in other developing countries much more in the developed worlds. Nurse educators are few and the available ones have much work load on their hands. There is need to develop curriculum to improve the quality of nursing education and also to guide nurse practitioner training program. APRNs are prepared with advanced didactic and clinical education, knowledge, skills and scope of practice in Nursing through post graduate education but there are many post qualification certification diplomas in nursing in Nigeria which if properly harnessed into post graduate programs will go a long way in advancing nursing education in Nigeria.

\section{The Contemporary Nurse}

Another major challenge to nursing profession in Nigeria is the nurses themselves. Many nurses in contemporary Nigeria are less caring, committed and dedicated to meeting the needs of the patients/clients [12]. Some nurses are not receptive to change, professional development and advancement. In nursing education and practice, some nurses tend to hold onto previous knowledge and skills without making the necessary effort to improve knowledge and skills in practice. Even though many nurses with Registered Nurse (RN) certificates are utilizing the opportunities created through work and study programmes to upgrade to BNsc degrees, many are equally not willing to accept the challenge of updating their knowledge and furthering their educational career. Even the mandatory continuing professional development programme (MCPDP) organized for nurses are seen by many as a means to renewal of license and not for the knowledge to be gained. Many others attribute their difficulty in staying abreast with new knowledge and furthering their education to the various financial challenges they face at home as it is not an uncommon knowledge that many nurses are breadwinners for the family.

The failure to keep abreast with the advancement in science and technology also affects the profession. Many nurses are not receptive to changes and new innovations in nursing. Accepting the nursing process as a scientific and systematic approach to nursing care was problematic to many nurses, understanding the concept of evidenced based nursing practice as a problem solving approach to clinical decision which integrates best available scientific evidence with best experimental evidence is yet to be understood and accepted by many and the concept of advanced nursing practice still seems farfetched and unrealizable to many nurses.

\section{The Shortage of Nurses}

Any reform in nursing must consider the supply and demand for nurses. Shortage in nursing refers to the inadequate number of nurses to care for patients at some professionally determined level [13]. In the various settings in which nurses practice the increasing awareness of patients/clients, issues associated with nursing practice such as autonomy, job satisfaction are all contributing factors to the shortage. Shortage of nurse educators within the education system is another call for concern. Equally 'brain drain' is another cankerworm that has eaten the nursing profession very deep as many brilliant professional nurses leave the country in their quest for greener pastures.

Policy making on health issues is yet another challenge to nursing profession and practice in the country. Nursing today is practiced in the midst of other health needs competing for the scare resource allocated to health. Unavailability of nurses or non involvement of nurse leaders in management budgetary meetings and the poor representation of nurses in decision making on health matters leads to nurses being marginalized in budget allocation and does not augur well for the profession. 


\section{Low Interest in Research}

Not many nurses are interested in research which is totally aimed at improving the quality of nursing care. There is need to promote research utilization through formation of nursing research/committee as a way to promote evidence based nursing and introduce advanced nursing practice into the country.

\section{Inter/Intra Professional Rivalry}

Inter/intra professional rivalry is another major factor hindering the advancement of nursing practice in Nigeria. Nurses face a lot of challenges from other healthcare professionals especially the doctors who feel they are the leaders of the healthcare team and see the advancement of nursing practice as a threat to their own jobs. To overcome this challenge, there is need to resolve the intra professional rivalry in nursing between different generations and based on educational background and pose a united front against the challenges facing the profession.

Equally, the gradual phasing away of mentorship in nursing which previously served as a way of bridging the gap between the older and younger generation or even between peers and subordinate in any relationship has impacted negatively on the profession. The dearth of the mentorship culture in Nursing needs revival so as to project the profession forward.

Other challenges include the unconducive and unsupportive nature of some work environment which lack modern equipment for practice and limit the ability of the nurse to learn and practice. Poor motivation of the nursing staff despite the huge workload they carry and minimal support towards educational advancement.

\section{Global strategies for removing barriers to aprn roles}

Globally, the APRN role is expanding and further developing based on international needs for expert practitioner to manage patient care as well as meet workforce needs. Due to the influence of changes in healthcare delivery, financial constraints and consumer demand on the evolution of advanced nursing practice, there has been wide divergence and variations in the emergence of the advanced nursing practitioner role. For the successful development and implementation of the role, policy, educational and regulatory standards are required.

Educational curricula need to be flexible and visionary to prepare the Advanced Nursing Practitioner for practice. The core concepts for ANP role are autonomy in clinical practice, pioneering professional and clinical leadership, expert practitioner and researcher. To achieve these core concepts, the advanced nursing practitioner must develop theoretical and clinical skills, meet the needs of the client, family and the community [14].

Strategies which can be implemented to remove barriers to APRN practice include

- Communicating about the APRN role and the value of APRN care to stakeholders including patients.

- Instituting media campaigns on the role of APRN care in patient care

- Conducting proactive lobbying to change restrictive APRN regulations.

- Highlight and demonstrate the impact of APRN care at institutional and national level.

- Demonstrating the value of APRN care by implementing innovative models that leverage APRN skills, knowledge and experience.

- Making APRN role visible by identifying contributions of APRN

- Educating health ministries, administrative entities, credentialing committees and medical staff about the practice of APRNs to assist in updating hospital bylaws.

- Encouraging patients/consumers cared for by APRNs to advocate for them as competent providers.

- Disseminating/publishing/present on exemplars in collaborative models that have demonstrated quality and safety improvements $[10,11]$.

\section{The possible ways forward for advanced nursing practice in Nigeria}

To solve the several challenges facing nursing practice in Nigeria and invariably advanced nursing practice, the following solutions could be proffered.

The Nursing and Midwifery Council of Nigeria need to meet up to its responsibility of regulating the standards of nursing/midwifery education and practice in Nigeria and develop a curriculum to guide nurse practitioner training program. The educational curricula need to be flexible and visionary to prepare nurses for advanced nursing practice. Dramatic changes and innovation in nursing education is necessary to reform the future of nursing practice in Nigeria. Nurse educators, students, consumers and nursing service personnel must work in partnership to design innovation educational system that meet the needs of the healthcare delivery system now and in the future [13]. Affiliating the various Schools of Nursing into Universities and upgrading the various diploma certificate courses to post graduate programmes will also go a long way in promoting the nursing profession in Nigeria. There is also need to bridge the existing gap between theory and practice. 
Nurses also need to change their mind set. Nursing needs to be recognized and respected as the professional career that it is. Nurses need to be more receptive to changes and professional development and advancement and embrace new knowledge and skills for nursing practice [12]. More trainings, seminars and workshops should be organized to keep nurses abreast with the advancement in science and technology and nurses should avail themselves of those opportunities to update their knowledge. Working institutions should also create environments that enable Nurses to further their education and advance their professional career. Technology should also be integrated into nursing education.

It is undeniable that there are many unemployed nurses seeking for employment opportunities. Government and private hospitals still need to do more in the area of employment to curb the menace of shortage of nurses. Better remunerations, motivations and welfare packages will make Nurses more comfortable in their working environment and prevent the constant migration of Nurses in the bid to seek for greener pastures.

Policy is needed to guide the development of advance nursing practice. As Nursing is competing with other fields and professionals for the scare resources allocated to health, it is of utmost importance that nurses' interest be adequately represented on health matters during decision making. Nurse leaders and managers must show interest in budgetary allocations.

Efforts should be made to ensure appreciable financial allocation to nursing programmes. The Nursing and Midwifery Council of Nigeria in conjunction with the Ministry of Health and with the support of relevant stakeholders should create a policy that will enhance the establishment of the Nurse practitioner program.

Nurses need to show more interest in research. Formation of nursing research/committee by the nursing and midwifery council of Nigeria to promote research among nurses is necessary [13]. There is need to understand that every research is aimed at improving the quality of nursing care and equally paving way and creating a conducive environment for advanced practice nursing. A career structure which formally recognizes the role of research and its relevance should be created.

Inter/intra professional rivalry which is the major factor hindering the advancement of nursing practice must be overcome. As a house divided among itself cannot stand, nurses need to unite and work together to advance the profession and pose a united front to other challenges presented by other professional bodies.

Mentorship should be revived in nursing. Mentoring has been described as an interactive process of learning in which the reward is twofold: reaching ones goal and professionally growing together [13]. There is exchange of ideas feedback, support, friendship, advice and information among other benefits. The practice of mentorship is gradually dying in nursing and need to be revived to promote the profession.

\section{Conclusion}

Advanced practice nursing is aimed at providing healthcare to the underserved population. Globally, the advanced practice nursing role is expanding and further developing based on international needs for an expert practitioner to manage patient care as well as meet workforce needs. As Nursing is evolving around the globe, Nursing in Nigeria should rise up to be able to compete with its counterparts around the world. Nursing is a dynamic profession that is research driven and to be able to meet up with the evolving healthcare needs, it is essential to incorporate the research findings and current trends into the nursing profession in Nigeria. For Advanced Practice Nursing to be successfully adopted and implemented in Nigeria, every nurse, nurse managers and all concerned should contribute their part to eliminate the challenges facing nursing practice in Nigeria.

\section{REFERENCES}

1. Kleinpell, R., Scanlon, A., Hibbet, D., Ganz, F., East, L., Fraser, D., Wong, F., Beauchesne, M. (2014). Addressing Issues Impacting advanced nursing practice worldwide.

2. International Council of Nurses. (2014). Definition and Characteristics of the Role. Retrieved from www.icnapnetwork.org.

3. Nursing and Midwifery Board-fact-sheet-advanced-practice-nursing(2013)

4. Brigitte, F., Yeong, W., Jasmine, Xin, Y., Lee, \& Wilson, W., San, T. (2017). The impact of the advanced Practice Nursing role on quality of care, clinical outcomes, patient satisfaction and cost in the emergency and critical care settings: a systematic review https://human-resources-health.biomedcentral.co...

5. Byrant, Lukosius, D., \& Martin, Misener, R. (2015). Advanced practice Nursing. an essential component of country level human resources for health. Retrieved from http://www.who.int/workforcealliance/knowledge/resources/ICNpolicybrief6advancedpracticeNursing.pdf 
6. International Council of Nursing. (2013). Retrieved from http:/icn-apnetwotk.org/.

7. Advanced Practice Nursing Fact Sheet 2020. Retrieved from https://nursejournal.org>advanced...

8. Helen, F.M. (2014). Interest in advanced practice nursing in Nigeria. Retrieved from https://international.aAPN.org

9. Naija, N. (2008). History. Retrieved from http://www.naijanurses.com

10. Robert Wood Johnson Foundation. (2013). Improving patient access to high quality care. How to fully utilize the skills, knowledge and experience of advanced practice registered nurses. Retrieved from www. rwjf.org/content/dam/farm/reports/issue briefs/2013/rwjf405378.

11. Brassard, A., \& Smolenski, M. (2011). Removing barriers to advanced practice registered nurse care. Insight on the issue, 55 Washington, DC AARP public policy institute http://campaignforaction.org/sites/default/files/removingbarriers-hospitalprivileges pdf

12. Obadiya, J.O. (2011). Nigeria Nursing: problems and prospects Obadiyajohn.blogspot.com/.../nigeria.

13. Clara, A. (2012). Re-envisioning nursing education and practice in Nigeria for the $21^{\text {st }}$ century.

14. Eileen, F., \& Rita, S. (2005). Advanced nursing practice: policy, education and role development. Journal of clinical nursing. 